* Corresponding author

Phone +421556022469

E-mail address: robert.hunady@tuke.sk

(Ing. Róbert Huňady, PhD.)

Article information

Article history: AMS-Volume16-No.2-00158-12

Received 16 January 2012

Accepted 11 March 2012

\section{Impact Assessment of Calibration Parameters on Accuracy Method of Digital Image Correlation}

\author{
Róbert Huňady*, Martin Hagara, Martin Schrötter
}

Department of Applied Mechanics and Mechatronics, Faculty of Mechanical Engineering, Letná 9, 04200 Košice, Slovak Republic

\section{BIOGRAPHICAL NOTES}

Ing. Róbert Huňady, PhD. (1981) he received M.S. degree in mechanical engineering from Technical University of Košice, Slovakia in 2007. In 2009, he attended EC Marie Curie Training Program SIMVIA2 at Czech Technical University of Prague, Czech republic. He finished his doctoral study in study field Applied mechanics in Faculty of mechanical engineering at Technical University of Košice, Slovakia in 2010. Since 2010 he has been working as lecture at Department of Applied Mechanics and Mechatronics at Technical University of Košice, Slovakia. His professional activity is oriented into the area of modern optical methods of experimental mechanics such as high-speed digital image correlation, electronic speckle pattern interferometry and laser doppler vibrometry. He is author or co-author of more than 30 journals, conference papers and works aimed particularly at experimental modal and vibration analysis.

Ing. Martin Hagara (1985) after successful completion of his study at the Gymnasium of Pavol Orszagh Hviezdoslav in Kezmarok he has started studies at the Faculty of Mechanical Engineering of the Technical university of Kosice. He graduated a bachelordegree study in Mechatronics in 2008. Thereafter he continued an engineer-degree study in Applied Mechanics. He defended his diploma thesis „Application of digital image correlation in solving problems of modal analysis" in 2010. Because of the results he has reached, he has been awarded the medal of excellent student by dean of the Faculty of mechanical engineering of the Technical university of Kosice. Nowadays he is a student of PhD-degree study in Applied mechanics, where he carries out research in methodics of digital image correlation in solving problems of mechanical structures dynamics.

Ing. Martin Schrötter (1986) after successful accomplishment of his study at the high school he has began studies at the Faculty of Mechanical Engineering of the Technical university of Kosice. He graduated with an honour a bachelor-degree study in General mechanics in 2008. Thereafter he continued an engineer-degree study of Applied Mechanics on the department of Applied mechanics and mechatronics. He defended his diploma thesis "Excitation drilling response of various rocks" in 2010 and accomplished this study with and honour. Nowadays, he is a PhD. student of Applied mechanics and is concentrating on operational modal analysis.

\section{KEY WORDS}

Digital image correlation, calibration, calibration parameters.

\section{ABSTRACT}

This article deals with factors, which influence accuracy of measured data obtained by 
method of digital image correlation, specifically by the system Q-450 from the company Dantec Dynamics. The attention is mainly focused on calibration of cameras and in detail it is remitted on its affect the accuracy of the results.

\section{Introduction}

The accuracy of the results obtained by the method of digital image correlation can be influenced by several factors; therefore, it is necessary in single process of measuring to put a strong emphasis to its correct setting. By application of appropriate procedures defined on basis of practical knowledge and experience it is possible to ensure such conditions, by which will results of measurement loaded by error to a minimum extent. This also minimizes the risk of necessity to repeat the experiment, what could be time consuming and expensive. In another part of the article we will mainly discuss the effect of cameras calibration by the system Q-450 from the company Dantec Dynamics on accuracy of results.

\section{Calibration of Cameras}

Among main factors, which influence accuracy of measured results we can include:

\section{- calibration of cameras,}

- sufficient sharpness and image contrast,

sufficient lighting of object with appropriate frequency of light source,

- if use a large number of cameras the same conditions of lighting for all cameras,

- quality and correct size of stochastic model formed on the surface of the object,

- size and possible non-linear distortion of facets in consequence to strong curvature of the sample.

The aim of calibration is definition of internal parameters (geometrical and optical characteristics) and also external parameters of cameras (relative position and camera rotation) in form of three dimensional location and rotation of camera imaging system in respect to the same global coordinate system. These parameters are necessary for consequential correlation of images and evaluation of measurement. Calibration must be performed under the same conditions as acquisition, i.e. at the same setting of cameras and lens. Software enables a user to calibrate system quickly and simply. User in menu for calibration chooses an appropriate calibration target, which size should approxi- mately respond to size investigated area of object. User rotates calibration target in the field of both cameras (Fig. 1).

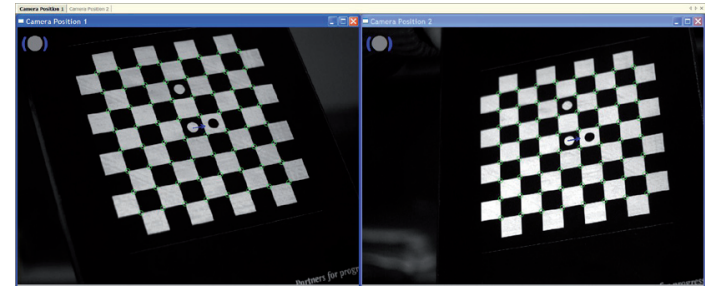

Fig. 1: Calibration procedure of cameras.

The cameras shoot different spatial positions of target, and so obtain sufficient amount of data for the calculation of necessary calibration parameters. Software in any position registers nodes of its checkerboard pattern and by the known geometry sets for every camera:

- focal length,

- location of the focus,

- radial and tangential curvature of the image,

- components of the vector displacement and rotation matrix.

The values of these parameters algorithm calculates for each registered location change of target. During calibration these values are changing depending on the analyzed position of target. Maximum number of calibration steps, which system is able to capture, is 25 .

Very simple and in practice often used calibration technique is this, which is based from so called Zhangov algorithm [1], [2]. This procedure is also used in optical correlation device Q-450 Dantec Dynamics and in general consists from following steps:

1. Creation of calibration pattern on the plane plate to size corresponding to the area of examined object $\rightarrow$ calibration target,

2. The acquisition of several images of calibration target in different positions obtained either by movement of the camera or movement of target,

3. Finding characteristics points with precisely defined location in the acquired images (Fig. 2),

4. Estimation of internal and external parameters of cameras by using mathematical algorithm,

5. Estimation the coefficients of radial distortion by using method of least squares,

6. Improvement of coefficients estimation. 


\section{$6 \mathrm{~mm}$}

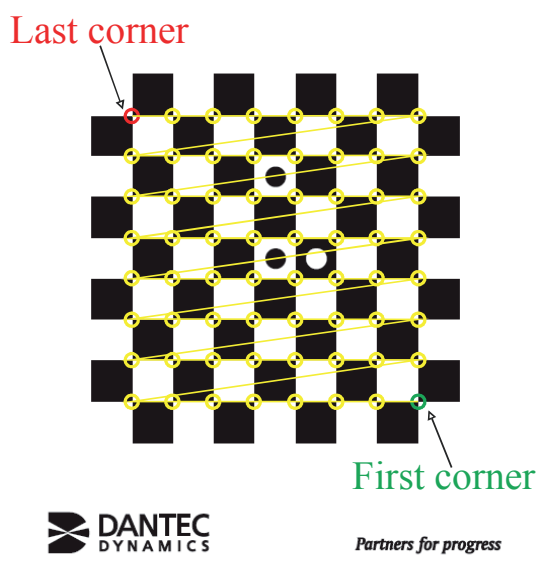

Fig. 2: Calibration target Dantec Dynamics $6 \mathrm{~mm}$, yellow colour schematically shows detection of characteristics points of known location.

In order to be ensured that in the image plane of camera is viewed a specific point of object, must be ensured coordinates transformation of a point object $P_{i}\left(X_{i}, Y_{i}, Z_{i}\right)$ into camera coordinate system $\left(u_{i}, v_{i}\right)$. Transformation consists of rotations or displacements and can be explained by a simple model of camera Obskura [3], [4], [5], [6]. This model presents view, where origin of the coordinate system of camera is identified with centre of projection and image plane is located in focal length $f$ in the positive direction of axis $z$ towards to object (Fig. 3).

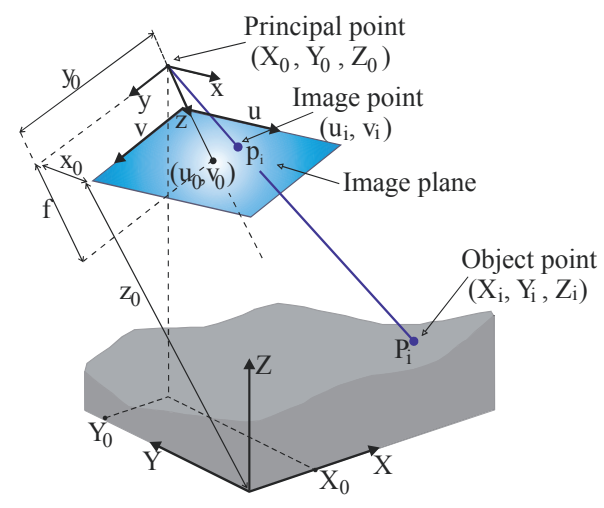

Fig. 3: View point of the object by model camera Obskura.

When beginning of camera coordinate system is identical with centre of projection, axis $z$ lies on extension of optical axis and axes $x$ and $y$ are parallel with axes $u$ and $v$ of image coordinate system, then for a view point of object $\mathbf{P}=[X, Y, Z]^{T}$ to image plane valid $\mathbf{p}=[u, v]^{T}$.

Expansion of these vectors to the following form $\mathbf{P}^{\prime}=[X, Y, Z, 1]^{T}$ or $\mathbf{p}^{\prime}=[u, v, 1]^{T}$ for relation between point $P$ in three dimensional space and its projection $p$ to two dimensional space valid:

$s \cdot p^{\prime}=A \cdot[R t] \cdot P^{\prime}$

where $\mathbf{R}$ is rotation matrix, $\mathbf{t}=[t x, t y, t z]^{T}$ is displacement vector, $\mathrm{s}$ is optional scaling factor and

$A=\left(\begin{array}{ccc}\alpha & \gamma & u_{0} \\ 0 & \beta & \nu_{0} \\ 0 & 0 & 1\end{array}\right)$

is so called internal camera matrix. Coefficients $\alpha$, $\beta$ present scaling factors in axis display $u$ or $v$ and parameter $\gamma$ describes distortion of both axes view.

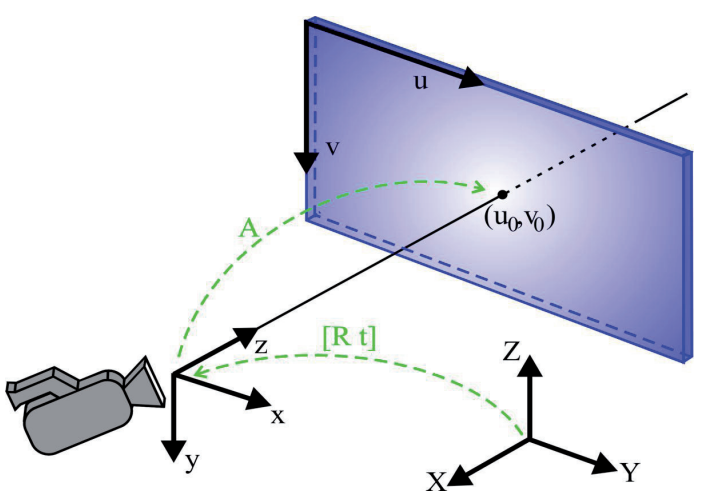

Fig. 4: Transformation of coordinates from general three- dimensional space to image coordinate system.

This mathematical model presents only kind of rough approximation of real operation running in cameras and its exploitation is suitable only in cases, when it is not required more accurate view. Obtain a more accurate projection model is reached by consideration of so called systematic distortion.

When it is present radial $\alpha_{r}$ and tangential $\alpha_{t}$ curvature of lens, occurs during projection point $P$ to deviation of straightness projection obtaining distorted projection point $P^{\prime \prime}$

$P^{\prime \prime}=\left(1+\alpha_{r}\right) \cdot P+\alpha_{t}$

In case of radial curvature of lens may be either 
positive or negative distortion and its size can be expressed by relation:

$\alpha_{r}=\alpha_{2} r^{2}+\alpha_{4} r^{4}+\alpha_{6} r^{6}+\alpha_{8} r^{8}+\ldots$

Tangential curvature is in comparison with radial curvature small and it is related with inequality of lens. Can be expressed by tangential parameters $t_{x}$ and $t_{y}$ in direction $x$ and $y$.

$\alpha_{t}=\left(\begin{array}{l}2 \cdot t_{x} \cdot x \cdot y+t_{y} \cdot\left(r^{2}+2 \cdot x^{2}\right) \\ t_{x} \cdot\left(r^{2}+2 \cdot y^{2}\right)+2 \cdot t_{y} \cdot x \cdot y\end{array}\right)$
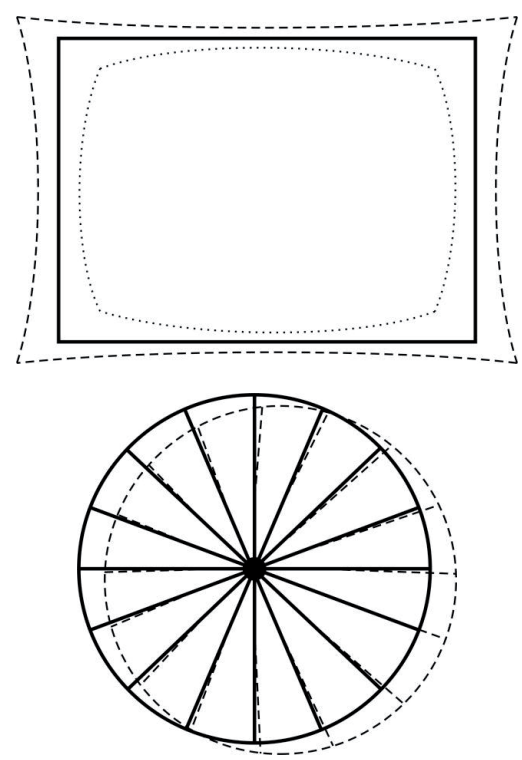

Fig. 5: Tangential (positive and negative) and radial distortion.

Since calibration data directly participated in the calculation of measured deformations and displacements, have the greatest impact on the accuracy of results. Inaccurate or incorrectly set image parameters can significantly distort values of measured parameters and can not be considered relevant.

\section{Impact Assessment of Calibration Parameters}

System Q-450 provides immediate feedback about quality and accuracy of set calibration parameters. A value indicator is so called residue of optimization algorithm, which indicates average uncertainty, with which system registers searched nodes of calibration target. The value of residue should be (depending on size of used target) less than $0.3-0.5$ pixel. Suitable value is not guaranteed of good calibration [7], [8], [9].

Graphs from Fig. 6 till Fig. 22 show an example of how change of individual calibration parameters and its estimated inaccuracy depends on calibration step but also on a size of used target. During calibration were used targets with width of one segment 8, 11 and $15 \mathrm{~mm}$ (Fig. 6). In all three cases were calibration performed under the same conditions, while system had to identify at least $80 \%$ of all nodal points of the target.
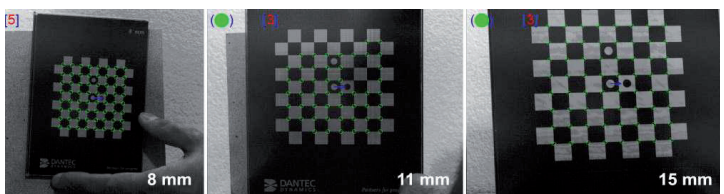

Fig. 6: Positioning of calibration targets during calibration.

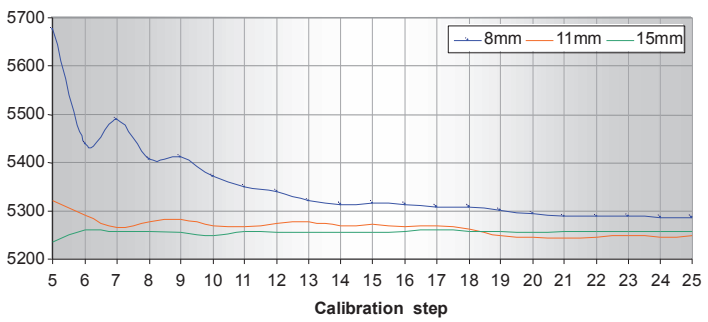

Fig. 7: Course of focal length $f_{x}$ depending on calibration step.

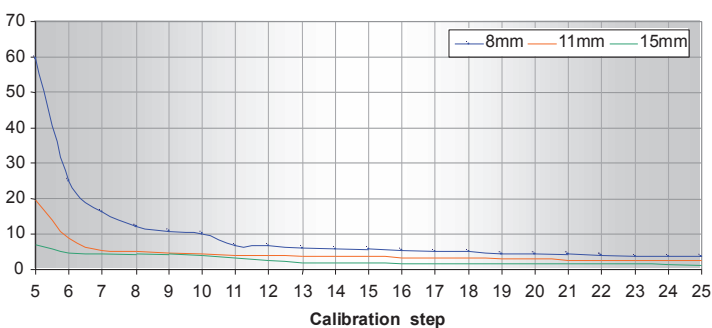

Fig. 8: Estimated inaccuracy of focal length $f_{x}$ depending on calibration step.

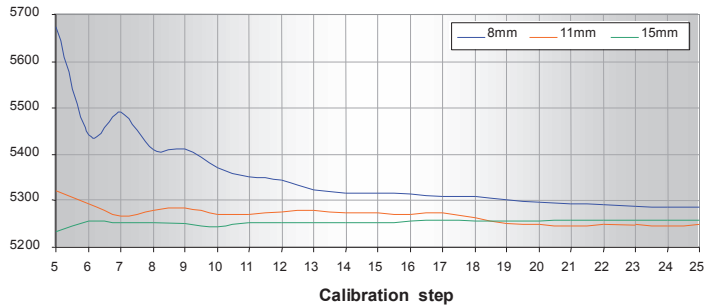

Fig. 9: Course of focal length $f_{y}$ depending on calibration step. 


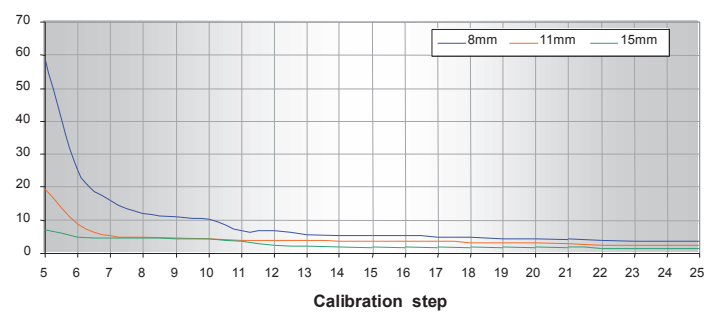

Fig. 10: Estimated inaccuracy of focal length $f_{y}$ depending on calibration step.

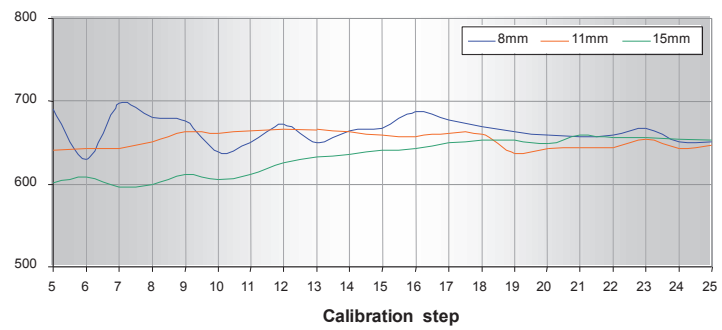

Fig. 11: Course of coordinates focus $x_{f}$ depending on calibration step.

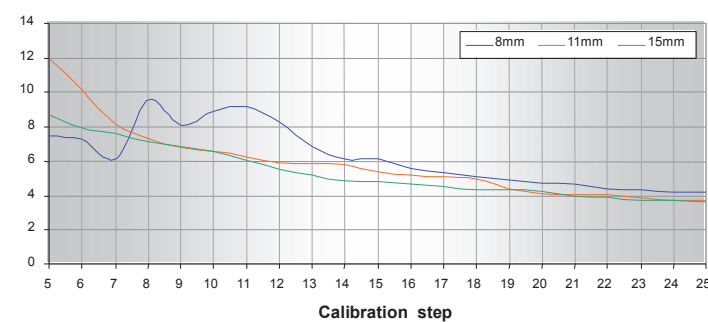

Fig. 12: Estimated inaccuracy of coordinates focus $x_{f}$ depending on calibration step.

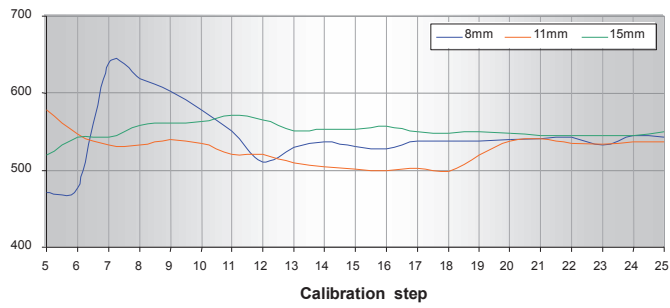

Fig. 13: Course of coordinates focus $y_{f}$ depending on calibration step.

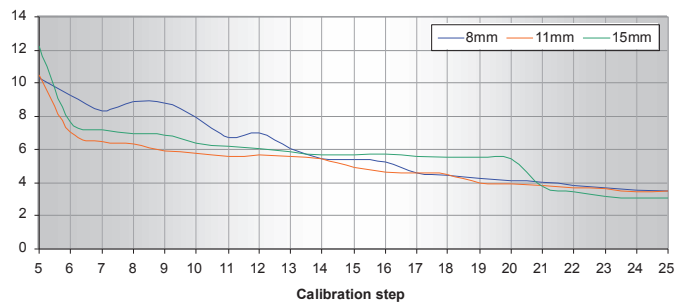

Fig. 14: Estimated inaccuracy of coordinates focus $y_{f}$ depending on calibration step.

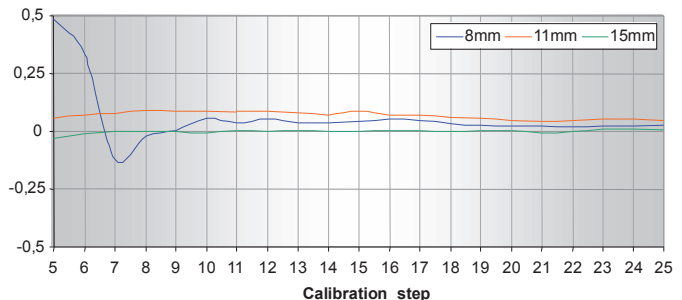

Fig. 15: Course of radial curvature of image $r^{2}$ depending on calibration step.

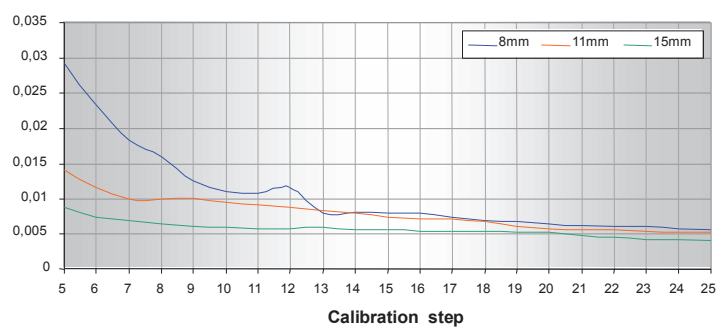

Fig. 16: Estimated inaccuracy of radial curvature $r^{2}$ depending on calibration step.

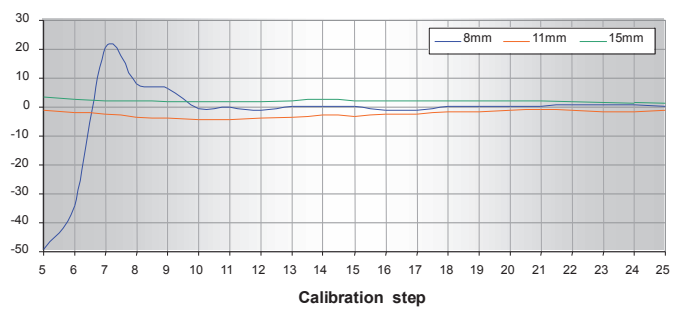

Fig. 17: Course of radial curvature of image $r^{4}$ depending on calibration step.

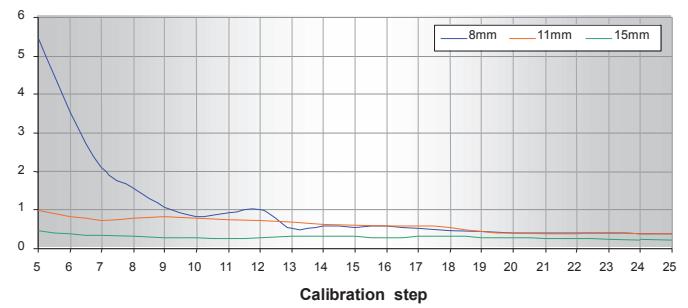

Fig. 18: Estimated inaccuracy of radial curvature $r^{4}$ depending on calibration step.

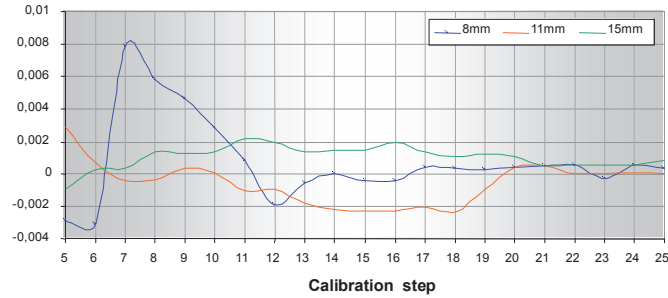

Fig. 19: Course of tangential curvature of image $t_{x}$ depending on calibration step. 


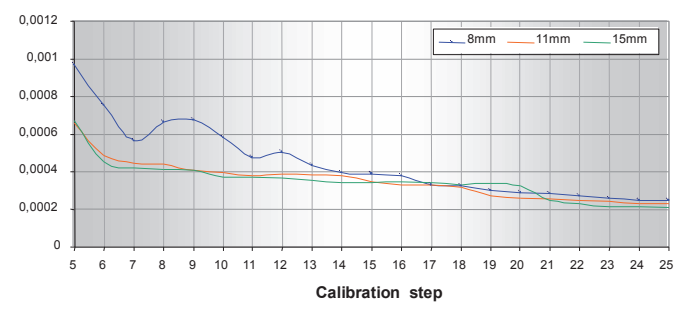

Fig. 20: Estimated inaccuracy of tangential curvature $t_{x}$ depending on calibration step.

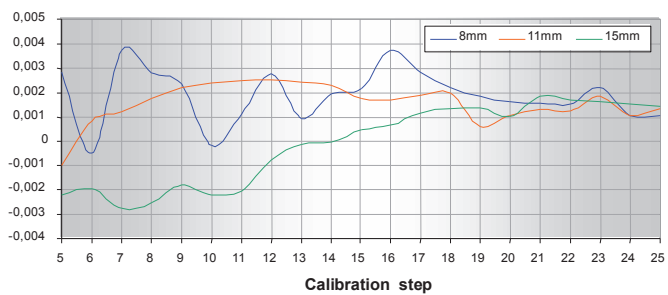

Fig. 21: Course of tangential curvature of image ty depending on calibration step.

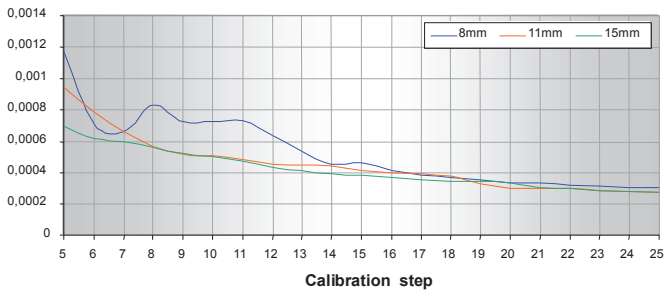

Fig. 22: Estimated inaccuracy of tangential curvature ty depending on calibration step.

The values of internal image parameters as focal length and coordinates of the focus after 12th step calibration change considerably in smaller extent; with increasing calibration steps the interval of changes is markedly narrowed. With the exception of external parameters plots from individual calibration targets are approached, and the most approaching is possible to observe after 20th step.

Estimated inaccuracies of image parameters with increasing steps are declined; the lowest value achieve in the last steps.

The effect of calibration parameters on accuracy results of correlation was assessed on basis of experiment, in which was captured by cameras planar surface of a square-shaped sample. A planar sample was chosen intentionally, with the aim to exclude the influence of systematic errors from the curvature of the surface. Surface of the sample captured by cameras was repeatedly correlated, which was al- ways used a different set with calibration data. It was possible to compare plots of evaluated parameters depending of number of calibration steps and size of used calibration target.

Files with the results of individual correlations were imported to environment program Matlab, where were analytically processed. In Fig. 23 there is showed dependence of the mean deviation for a form of reconstructed contour in relation to surface towards perfect planar surface depending on number of calibration steps. Even though average deviations of the shape with an increasing number of steps are reduced, its decrease is not as important as in case of absolute wide of these range deviations, which gives a much better picture of impact calibration steps number on the accuracy of reconstruction correlated contour (Fig. 24).

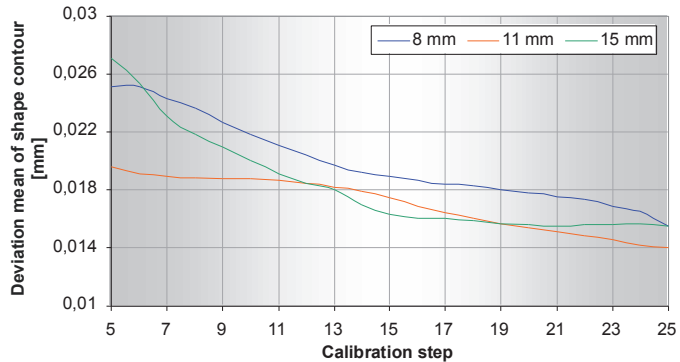

Fig. 23: Relation of deviation mean shape contour on number of calibration steps.

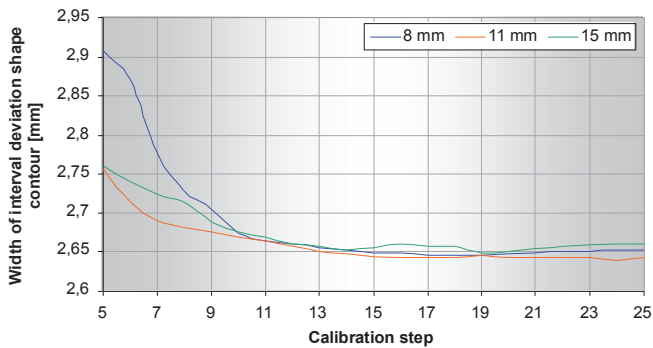

Fig. 24: Relation of width interval deviation shape contour on number calibration steps.

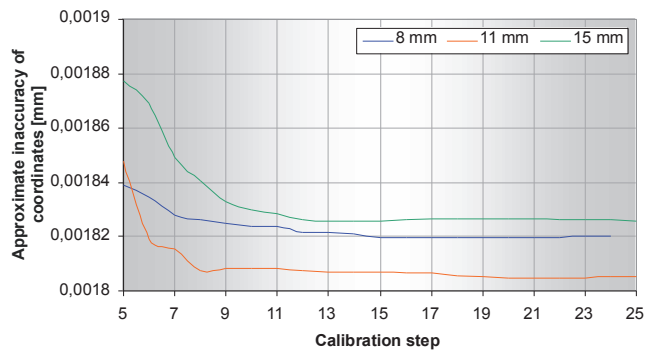

Fig. 25: Relation of average inaccuracies coordinates on number of calibration steps. 
The second evaluation indicator was approximate inaccuracy coordinates of contour points. On Fig. 25 are shown the courses of mean value of these inaccuracies.

Similarly, as with number of steps is interval deviation form narrowed, decrease also courses of estimated inaccuracies of coordinates. Approximately, from tenth calibration step is already decline of values less marked.

\section{Conclusion}

Based on analysis of reached experiment results can reach the following conclusions:

- calibration process affects the values of measurements,

- under normal conditions accuracy of calibration parameters with number of calibration steps increase,

- deviations of calibration parameters are with every other step decreasing,

- as well as the inaccuracies of results fall.

Choice of appropriate calibration target is paramount. A target should be all seen in the picture of both cameras. Its size should approximately answer to size of investigated area sample. During filming a target should be located in the depth of focus and in a distance approximately corresponding to the distance of sample. Problems with detection of nodes are possible to influence changing of target position, changing light conditions, changing closing time or eventually by change of calibration settings. Calibration procedure itself is not difficult; therefore, in case of doubts to recommend repeat it and compare the values of individual parameters. Depending on the demands of experiment is possible for optimal number consider 12 calibration steps.

\section{Acknowledge}

The paper has been created realization of project "Center for research of control of technical, environmental and human risks for permanent development of production and products in mechanical engineering" (IMTS:26220120060), based on operating program support Research and Development financed from European Regional Development Fund and by Scientific Grant Agency VEGA MŠ SR for the support of this work under Project No. 1/0937/12.

\section{References}

[1] ZHANG Z. A Flexible New Technique for Camera Calibration. In IEEE Tranactions on pattern analysis and machine intelligence [online]. November 2000, vol. 22, no. 11, p. 1330-1334. URL:<http://research.microsoft.com/en-us/um/ people/zhang/papers/zhangpami-02-calib.pdf>

[2] ZHANG Z. A Flexible New Technique for Camera Calibration. In Microsoft Research Technical Report MSR-TR-98-71, Microsoft Corporation, Redmond, WA 98052, 2 December 1998.

[3] BECKER, T. et al. Error Estimations of 3D Digital Image Correlation Measurements. In Dantec Dynamics/Technical Note, 2008.

[4] PARENT R. Computer Animation - Algorithms and Techniques. Morgan Kaufmann Publishers Inc., 2002. 527 p. ISBN: 1-55860-579-7.

[5] HEIKILLÄ J. Geometric Camera Calibration Using Circular Control Points. In IEEE Tranactions on pattern analysis and machine intelligence. October 2000, vol. 22, no. 10, p. 10661077.

[6] LICHTENBERGER R. - SCHREIER H. Non-contacting measurement technology for component safety assessment. LIMESS Messtechnik u. Software GmbH, D-75180 Pforzheim.

[7] DANTEC DYNAMICS GmbH. 2008. Istra4D / Software Manual Q-450 System

[8] HUŇADY, R.: Možnosti využitia metódy digitálnej obrazovej korelácie $v$ aplikáciách dynamiky. Dizertačná práca. Košice: Technická univerzita v Košiciach, Strojnícka fakulta, 2010.

[9] Trebuňa, F., Huňady, R., Bobovský, Z., Hagara, M.: An application of high-speed digital image correlation in determination of modal parameters, In: Acta Mechanica Slovaca, vol. 16, no. 4, 2012. 